\title{
ON-LINE FAULT DETECTION AND LOCALIZATION IN THREE-PHASE INDUCTION MOTOR DRIVE SYSTEMS
}

\author{
Arafa S. Mohamed, Haitham Z. Azazy and Ashraf S. Zein El Din \\ Electrical Engineering Department, Faculty of Engineering, Shebin El-Kom, \\ Minoufiya University, Egypt
}

\begin{abstract}
Induction motors are robust machines used not only for general purposes, but also in hazardous locations and severe environments. Although these are very reliable, they are susceptible to many types of faults. However, induction motor drive faults can be detected in an early stage, in order to prevent the complete failure of the motor drive and ward off unexpected production costs. In this paper, a simple diagnostic and detection method that allows the real-time detection and localization of single and multiple open-circuit faults in the voltage source inverter (VSI) for a three-phase induction motor drive system using just the motor phase currents, is presented. A model of the system is built using MATLAB/SIMULINK. Simulation results are presented showing the diagnostic method performance under distinct operating conditions.
\end{abstract}

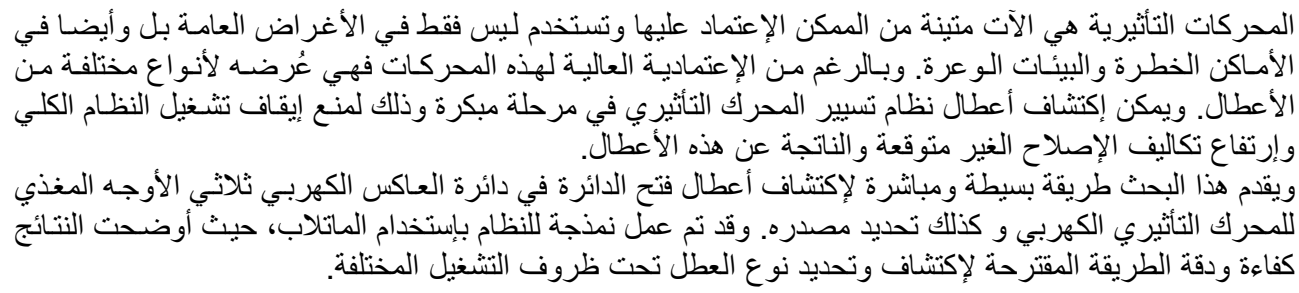

Keywords: Induction motor drive, fault diagnosis, inverter faults, open-circuit fault, reliability.

\section{INTRODUCTION}

Induction motors are used worldwide as the workhorse in industrial applications. Such motors are robust machines used not only for general purposes, but also in hazardous locations and severe environments. Furthermore, induction motors are highly reliable, require low maintenance, and relatively have high efficiency [1-5].

Although these motors are highly reliable, they are susceptible to many types of faults. Such faults can become catastrophic and cause production shutdowns, personal injuries, and raw material waste. However, induction motor faults can be detected in an early stage, allowing us to prevent a complete failure of the motor and its consequent unexpected production costs [3].
Therefore, in order to preclude this harmful influence as well as to improve the system reliability, the development of fault diagnostic methods has attracted a lot of interest during the recent past [4]. Furthermore, for critical applications where fault tolerant systems are highly recommended, temporary remedial actions, that allow the system to continue operating under faulty conditions, are also strongly based on real-time diagnostic algorithms. They can be easily integrated into the drive controller, helping to improve its reliability and reduce the negative consequences caused by unintentional stoppages [5].

Some statistical studies are introduced to show the components most susceptible to failures. These studies show that about $38 \%$ of the failures in variable speed ac drives in industry are mostly found in power equipment and $53 \%$ in the control circuits [6]. Also, an industry based survey regarding the 
reliability in power electronic converters show that power devices, capacitors and gate control circuits are the most susceptible components [7]. Recently, another study shows that semiconductor, soldering and printed circuit board failures in device modules totals $60 \%$ of converter system failures [8].

Therefore, it is possible to conclude that a very high percentage of failures are reflected on power switch faults, since a failure in a gate control circuit results in a switch open-circuit fault [9].

Power switch failures can be broadly classified as short-circuit faults and open-circuit faults. Inverter typical protection methods include protection against overcurrent or short-circuit, but they do not include protection against open-circuit faults. Then, opencircuit faults can remain undetected for an extended period of time, leading to potential secondary faults in the converter [10].

Based on the facts mentioned earlier, the research work development on reliable fault diagnostic methods for open-circuit faults is so significant [910].

In reference [11] the current Park's vector approach was proposed as a fault diagnostic tool for inverter faults. Although this approach allows for the visualization of all the possible distinguishable inverter fault modes, it requires very complex pattern recognition algorithms which are not suitable for integration into the drive controller. However, many fault diagnostic methods rely on this first proposed approach.

In reference [12] the average current Park's vector approach was introduced, in which the faults are detected when the vector modulus is different from zero and the faulty switch is localized by the vector phase. Further developments were reported in [13], including the derivative of the vector phase.

Other works based on Park's vector approach were published in [14-15], using probabilistic and fuzzybased approaches for the boundaries definition between the different patterns under both healthy and faulty conditions, in order to avoid false alarms and increase the diagnostic certainty.

The major drawbacks of the previous methods are the load dependence and the sensitivity to transients, which result in low diagnostic effectiveness for low load levels and false alarms during transients.

In an attempt to overcome these weaknesses, the normalized average currents were suggested and refined in [16]. Later, in [17] an extension to the normalized average currents was proposed and the detection of multiple faults achieved. These enhancements imply higher complexity and larger detection times.

In Reference [18] an observer-based diagnosis scheme for single and simultaneous open-switch faults in induction motor drives was addressed. The algorithm proves to be load independent and does not require additional sensors. However, as main drawbacks, the method implementation is not straightforward, being computationally demanding and requiring the knowledge of the machine parameters.

In Reference [19] a fast detection of open-circuit and short-circuit faults in IGBTs was presented. A novel failure-detection technique and its analog circuit were proposed and applied to a three-phase induction motor drive. The obtained results prove that a fast detection time can be achieved. Nevertheless, the analog circuit requires some voltage measurements, which increases the system complexity, and the technique cannot be applied to all power devices since it strongly depends on the power device characteristics.

In this paper a simple diagnostic and detection method is presented that allows the real-time detection and localization of single and multiple open-circuit faults for a VSI-fed three-phase induction motor controlled by field-oriented control (FOC) using just the motor phase currents. Simulation results are presented showing the algorithm performance under distinct operating conditions.

\section{FAULT DIAGNOSIS ALGORITHM}

The proposed diagnostic method shown in Fig. 1 results from an enhanced version of the method firstly presented in [20]. This technique utilizes motor variables already used by the main control, avoiding the use of extra sensors and the subsequent increase of the system complexity and costs.

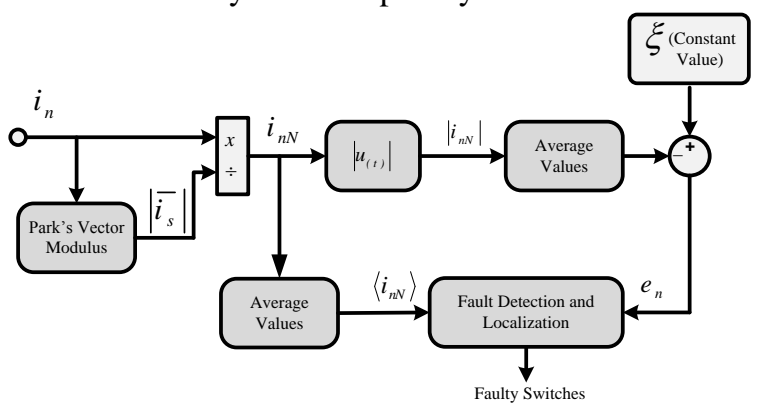

Fig. 1 Block diagram of the fault diagnosis method

The normalization of measured motor phase currents using the modulus of Park's vector is used to face the problems associated with the dependency of the machine on its operating conditions and the issue of false diagnostics which is defined as:

$$
\begin{aligned}
& i_{d}=\sqrt{\frac{2}{3}} i_{a}-\frac{1}{\sqrt{6}} i_{b}-\frac{1}{\sqrt{6}} i_{c} \\
& i_{q}=\frac{1}{\sqrt{2}} i_{b}-\frac{1}{\sqrt{2}} i_{c}
\end{aligned}
$$


where $i_{d}$ and $i_{q}$ are the Park's vector components and $i_{a}, i_{b}$, and $i_{c}$ the motor phase currents.

The Park's vector modulus $\left|\bar{i}_{s}\right|$ is given by:

$\left|\overline{i_{s}}\right|=\sqrt{i_{d}^{2}+i_{q}^{2}}$

The normalization is performed by dividing the motor phase currents by Park's vector modulus. The obtained normalized motor phase currents $i_{n N}$ are given by:

$i_{n N}=\frac{i_{n}}{\left|\overline{i_{s}}\right|}$

where $n=a, b, c$. Under healthy operating conditions, and neglecting the low amplitude high frequency noise, the motor is supplied by a perfectly balanced three-phase sinusoidal current system that can be given by:

$i_{a}=\mathrm{I}_{m} \sin \left(\omega_{s} t\right)$

$i_{b}=\mathrm{I}_{m} \sin \left(\omega_{s} t-\frac{2 \pi}{3}\right)$

$i_{c}=\mathrm{I}_{m} \sin \left(\omega_{s} t+\frac{2 \pi}{3}\right)$

where $I_{m}$ is the current's maximum amplitude and $\omega_{s}$ is the motor angular frequency. It can be proven that Park's vector modulus can be given by:

$\left|\overline{i_{s}}\right|=\sqrt{\frac{3}{2}} \mathrm{I}_{m}$

As a consequence of this normalization process, the normalized motor phase currents will always take values within the range of $\pm \sqrt{2 / 3}$, independent of the measured motor phase current amplitude, since:

$$
\begin{aligned}
& i_{a N}=\sqrt{\frac{2}{3}} \sin \left(\omega_{s} t\right) \\
& i_{b N}=\sqrt{\frac{2}{3}} \sin \left(\omega_{s} t-\frac{2 \pi}{3}\right) \\
& i_{c N}=\sqrt{\frac{2}{3}} \sin \left(\omega_{s} t+\frac{2 \pi}{3}\right)
\end{aligned}
$$

Under these conditions, the average absolute values of the three normalized motor phase currents $\left\langle\left|i_{n N}\right|\right\rangle$ are given by:

$\omega_{s} \int_{0}^{\frac{1}{\omega_{s}}}\left|i_{n N}\right| d \omega_{s} t=\frac{1}{\pi} \sqrt{\frac{8}{3}}$

(8)

Finally, the three diagnostic variables $e_{n}$ are obtained from the errors of the average absolute values of the normalized currents, given by:

$e_{n}=\xi-\left\langle\left|i_{n N}\right|\right\rangle$ where $\xi$ is a constant value equivalent to the average absolute value of the normalized motor phase currents under normal operating conditions given by (8), that is:

$\xi=\frac{1}{\pi} \sqrt{\frac{8}{3}} \approx 0.5198$

The three diagnostic variables defined in (9) have specific characteristics which allow for diagnosis of the inverter fault. Under normal operating conditions, these diagnostic variables will take values equal zero. If an inverter open-circuit fault is introduced, at least one of the diagnostic variables will assume a distinct positive value. Therefore, the errors $e_{n}$ can be effectively used to detect an abnormal inverter behavior.

But these variables just carry information about the affected phases, so, they are not capable of performing a complete inverter diagnosis. Hence, this information together with the currents' average values $\left\langle i_{n N}\right\rangle$, can be used to identify the faulty power switches. To achieve this, the fault variables can be formulated according to the following expressions:

$$
E_{n}=\left\{\begin{array}{lll}
N & \text { for } & e_{n}<0 \\
0 & \text { for } & 0 \leq e_{n}<\kappa_{f} \\
P & \text { for } & \kappa_{f} \leq e_{n}<\kappa_{d} \\
D & \text { for } & e_{n} \geq \kappa_{d}
\end{array}\right.
$$

$S_{n}=\left\{\begin{array}{lll}L L & \text { for } & \left\langle i_{n N}\right\rangle \leq-\kappa_{s} \\ L & \text { for } & \left\langle i_{n N}\right\rangle<0 \\ H & \text { for } & \left\langle i_{n N}\right\rangle>0 \\ H H & \text { for } & \left\langle i_{n N}\right\rangle \geq \kappa_{s}\end{array}\right.$

Where $k_{f}, k_{d}$ and $k_{s}$ are the threshold values.

The values taken by $E_{n}$ and $S_{n}$ allow generating a distinct fault signature which corresponds to a specific faulty operating condition. Taking this into account and considering a typical motor drive system with a voltage source inverter supplying an ac motor (Fig. 2), the generated fault signatures allow to detect and localize 27 possible combinations of faulty IGBTs, as shown in Table 1.

Table 1 Diagnosis signatures for faulty switches identification

\begin{tabular}{|c|c|c|c|c|c|c|}
\hline $\begin{array}{c}\text { Faulty } \\
\text { Switches }\end{array}$ & $E_{a}$ & $E_{b}$ & $E_{c}$ & $S_{a}$ & $S_{b}$ & $S_{c}$ \\
\hline $\mathrm{T} 1$ & $\mathrm{P}$ & $\mathrm{N}$ & $\mathrm{N}$ & $\mathrm{L}$ & & \\
\hline $\mathrm{T} 2$ & $\mathrm{P}$ & $\mathrm{N}$ & $\mathrm{N}$ & $\mathrm{H}$ & & \\
\hline T3 & $\mathrm{N}$ & $\mathrm{P}$ & $\mathrm{N}$ & & $\mathrm{L}$ & \\
\hline $\mathrm{T} 4$ & $\mathrm{~N}$ & $\mathrm{P}$ & $\mathrm{N}$ & & $\mathrm{H}$ & \\
\hline $\mathrm{T} 5$ & $\mathrm{~N}$ & $\mathrm{~N}$ & $\mathrm{P}$ & & & $\mathrm{L}$ \\
\hline $\mathrm{T} 6$ & $\mathrm{~N}$ & $\mathrm{~N}$ & $\mathrm{P}$ & & & $\mathrm{H}$ \\
\hline $\mathrm{T} 1, \mathrm{~T} 2$ & $\mathrm{D}$ & & & & & \\
\hline
\end{tabular}




\begin{tabular}{|c|c|c|c|c|c|c|}
\hline T3, T4 & & D & & & & \\
\hline T5, T6 & & & D & & & \\
\hline T1, T3 & P & P & N & L & L & H \\
\hline T2, T4 & P & P & N & H & H & L \\
\hline T1, T5 & P & N & P & L & H & L \\
\hline T2, T6 & P & N & P & H & L & H \\
\hline T3, T5 & N & P & P & H & L & L \\
\hline T4, T6 & N & P & P & L & H & H \\
\hline T1, T4 & & & & LL & HH & \\
\hline T3, T2 & & & & HH & LL & \\
\hline T1, T6 & & & & LL & & HH \\
\hline T5, T2 & & & & HH & & LL \\
\hline T3, T6 & & & & & LL & HH \\
\hline T5, T4 & & & & & HH & LL \\
\hline T1, T3, T6 & P & P & N & LL & L & HH \\
\hline T2, T4, T5 & P & P & N & HH & H & LL \\
\hline T1, T5, T4 & P & N & P & L & HH & LL \\
\hline T2, T6, T3 & P & N & P & H & LL & HH \\
\hline T3, T5, T2 & N & P & P & HH & LL & L \\
\hline T4, T6, T1 & N & P & P & LL & HH & H \\
\hline
\end{tabular}

For all the considered operating conditions, a load level equivalent to $50 \%$ of the motor rated torque is assumed, together with a reference speed of 100 $\mathrm{rad} / \mathrm{sec}$. The threshold values $k_{f}, k_{d}$ and $k_{s}$ were set to be equal to $0.06,0.265$ and 0.3 , respectively. The exact procedure on how these values were chosen is explained in a more detailed way in Section 4.

Four distinct faulty operating conditions are considered: a single IGBT open-circuit fault, a single-phase open-circuit fault, a double open-circuit fault in two upper power switches and a crossed double fault in two different legs. All the power switch open-circuit faults are effected by removing their respective gate signals, keeping the antiparallel diodes connected. Also, to evaluate the diagnostic method performance and to analyze its robustness against the issue of false alarms, a high amplitude load and speed transients are introduced.

\subsection{Single IGBT Open-Circuit Fault}

The simulation results of the motor phase currents, diagnosis variables and current average values are presented in Fig. 3.

A single power switch open-circuit fault in IGBT T3 is introduced at the instant $t=0.48 \mathrm{sec}$. The diagnostic variable of the corresponding affected phase $E_{b}$ increases immediately, converging to a value of 0.23 . The remaining diagnostic variables $E_{a}$ and $E_{c}$ will decrease until they reach values of about -0.076 , 0.089 , respectively.

At the instant $t=0.4927 \mathrm{sec}$, after $12.7 \mathrm{msec}$ of the fault occurrence, the open-circuit fault is detected and identified by the diagnostic method.

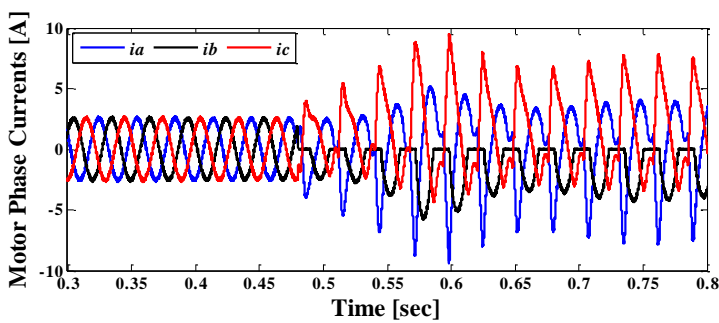

(a) established by simply analyzing the variables' behavior for different faulty operating conditions and taking into account a tradeoff between fast detection and robustness against false alarms. A more detailed explanation regarding the selection of these thresholds is presented in Section 4.

\section{SIMULATION RESULTS}

A rotor field-oriented control of a three-phase induction motor drive system has been modeled and simulated using the MATLAB/SIMULINK environment. The parameters of the induction motor are given in Table 2 .

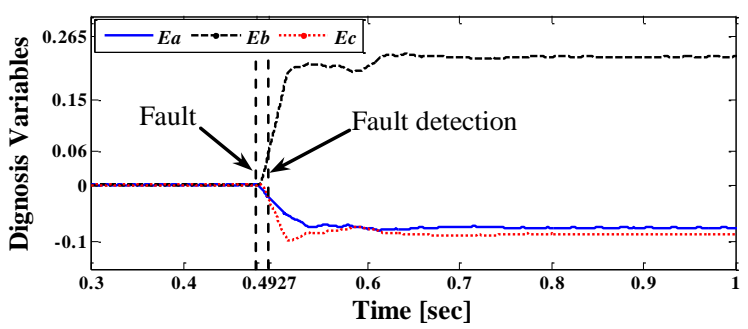

(b) 


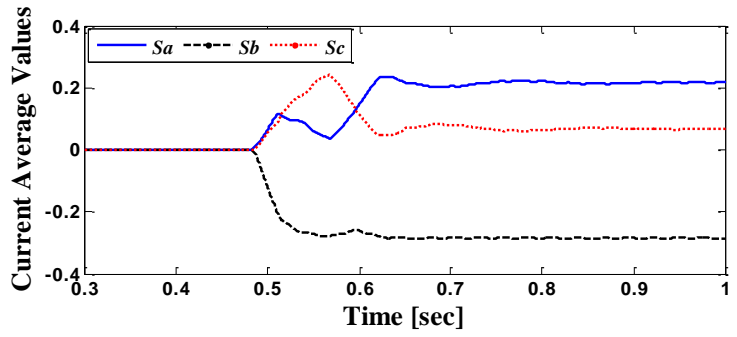

(c)

Fig. 3 Simulation results for a single power switch opencircuit fault in IGBT T3 of the (a) motor phase currents, (b)

diagnosis variables and (c) current average values.

\subsection{Single-Phase Open-Circuit Fault}

The simulation results of the motor phase currents, diagnosis variables and current average values are presented in Fig. 4.

At the instant $t=0.89 \mathrm{sec}$, the gate signals are removed from the IGBTs T5 and T6, resulting in a single-phase open-circuit fault in phase $c$. the diagnostic variable of the corresponding affected phase $E_{c}$ increases, converging to a value of 0.514 . The remaining diagnostic variables $E_{a}$ and $E_{b}$ will decrease until they reach a value of about -0.19 each. The information provided by the diagnosis variables $S_{n}$ is irrelevant in this case.

The abnormal behavior in phase $c$ is detected after 12.9 msec of the fault occurrence. The final confirmation of a single-phase open-circuit fault in this leg is detected at $t=0.9182 \mathrm{sec}$ (after $28.2 \mathrm{msec}$ of the fault occurrence) when the diagnosis variable $E_{c}$ reaches the threshold $k_{d}$.

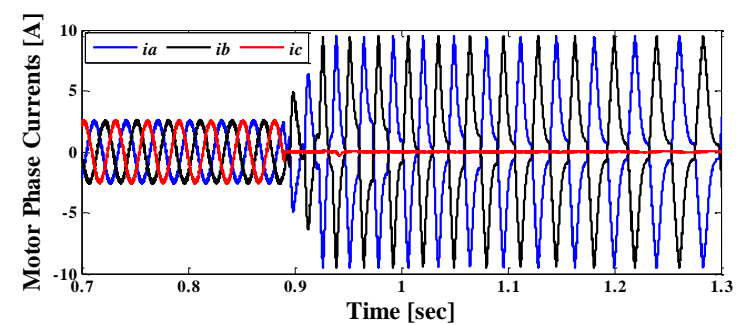

(a)

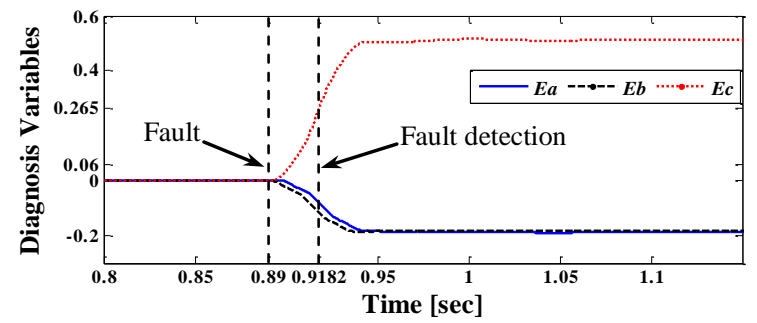

(b)

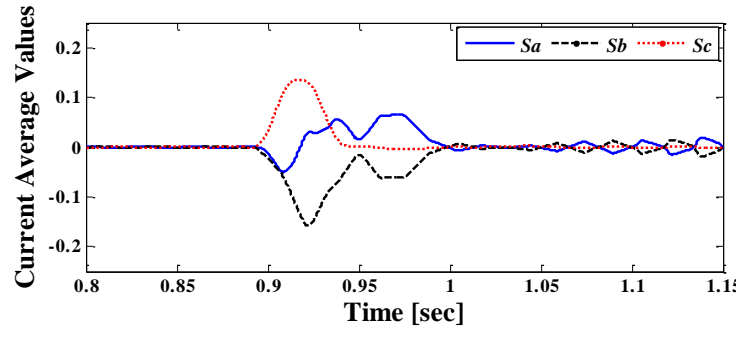

(c)

Fig. 4 Simulation results for a single phase open-circuit fault in phase $c$ of the (a) motor phase currents, (b) diagnosis variables and (c) current average values.

\subsection{Double Power Switch Open-Circuit Fault}

The simulation results of the motor phase currents, diagnosis variables and current average values are presented in Fig. 5. A double power switch open-circuit fault in IGBTs T1 and T3 at the instant $t=1.2 \mathrm{sec}$ is introduced. Immediately, the diagnostic variables $E_{a}$ and $E_{b}$ corresponding to the faulty phases will increase and reach values higher than the threshold $k_{f}$. The other diagnostic variable $E_{c}$ corresponding to the faultless phase will decrease and reach a negative value. At the instant $t=1.2247$ $\mathrm{sec}$, after $24.7 \mathrm{msec}$ of the fault occurrence, the double switch open-circuit fault is detected and identified by the diagnostic method.

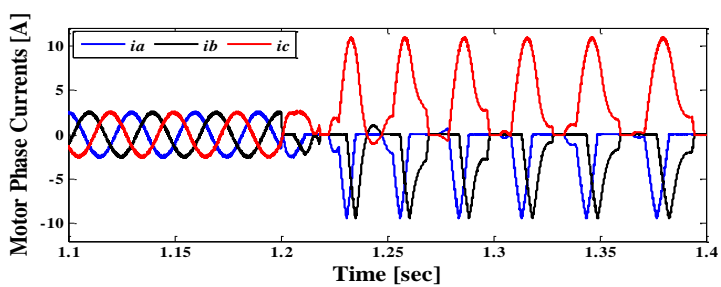

(a)

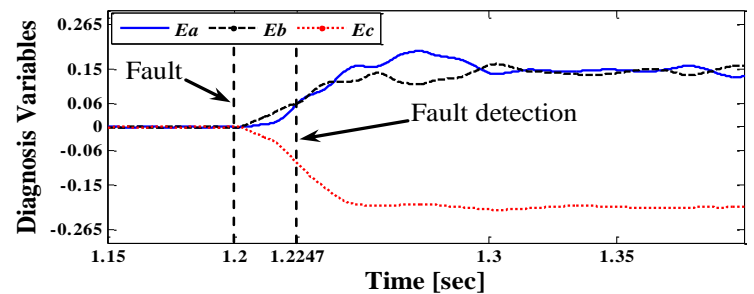

(b)

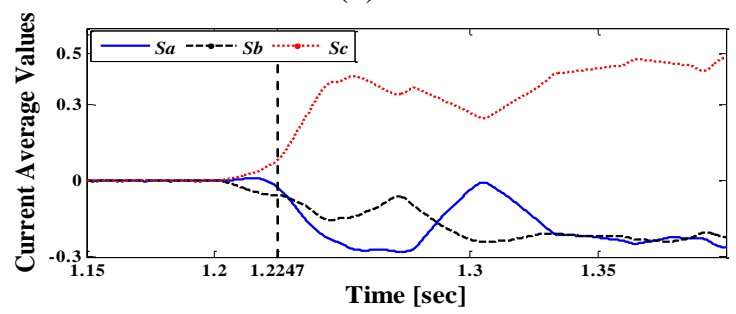

(c)

Fig. 5 Simulation results for a double power switch opencircuit fault in IGBTs T1 and T3 of the (a) motor phase currents, (b) diagnosis variables and (c) current average values. 


\subsection{Crossed Double Fault in Two Different Legs}

The simulation results regarding the motor phase currents, diagnosis variables and current average values are presented in Fig. 6.

A crossed double power switch open-circuit fault in IGBTs T2 and T3 at the instant $t=0.45 \mathrm{sec}$ is introduced. As a consequence, the current average values of phase $a$ and phase $b$ will reach values approximately about $0.43,-0.42$, respectively. The information provided by the diagnosis variables $E_{n}$ is irrelevant in this case.

At the instant $t=0.4793 \mathrm{sec}$, after $29.3 \mathrm{msec}$ of the fault occurrence, the crossed double switch opencircuit fault is detected.

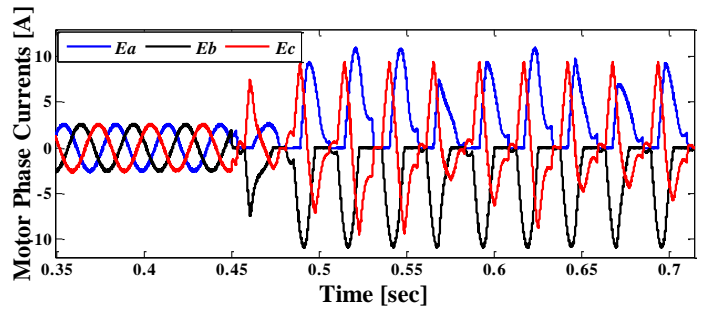

(a)

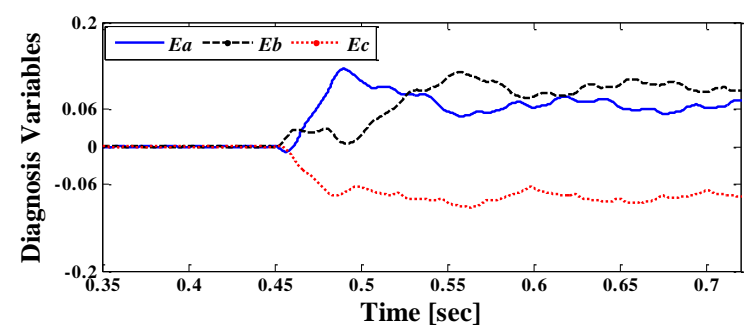

(b)

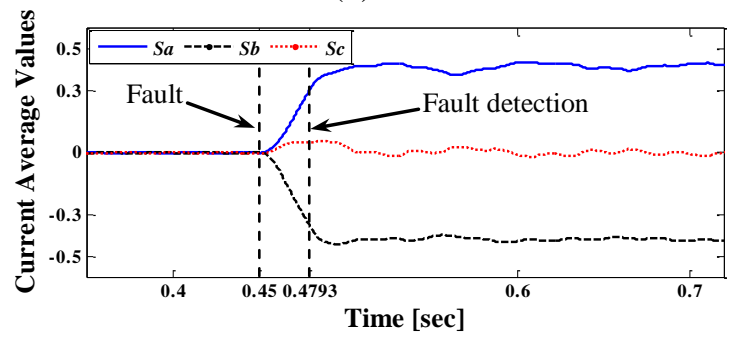

(c)

Fig. 6 Simulation results for a crossed double power switch open-circuit fault in IGBTs T2 and T3 of the (a) motor phase currents, (b) diagnosis variables and (c) current average values.

\subsection{Algorithm Performance During Transients}

With the aim of analyzing the diagnostic algorithm robustness against false alarms, strong load and speed variations were applied to the motor drive system. The obtained results can be seen in Fig. 7, regarding the motor phase currents, diagnostic variables, current average values, motor speed and electromagnetic torque.

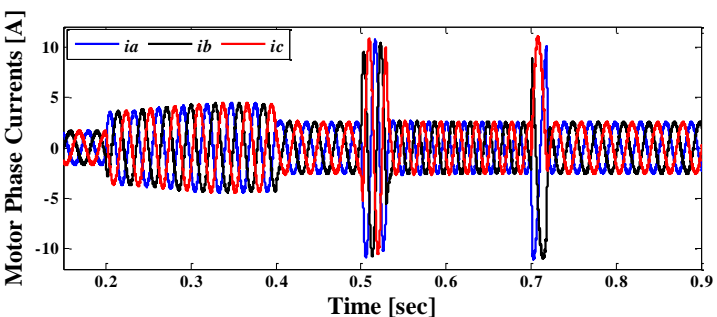

(a)

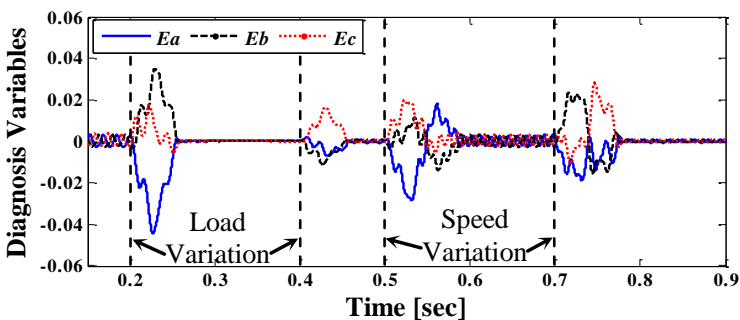

(b)

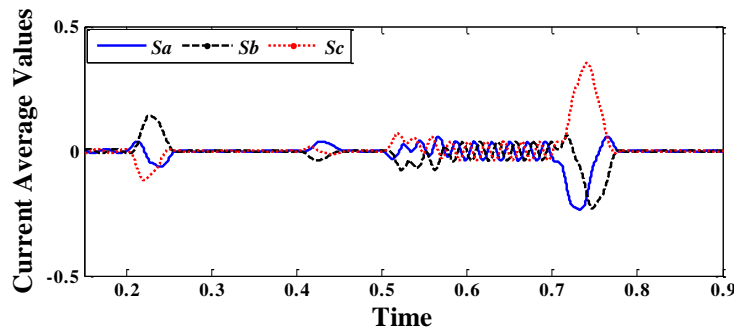

(c)

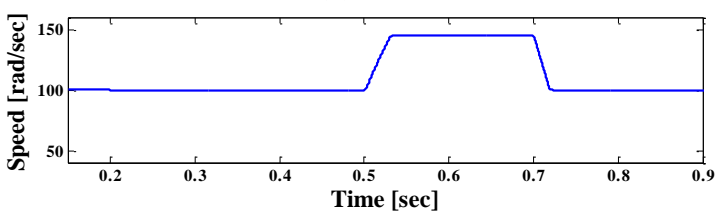

(d)

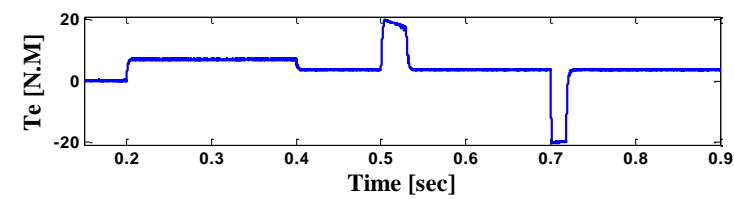

(e)

Fig. 7 Simulation results during load and speed variations of the (a) motor phase currents, (b) diagnosis variables, (c) current average values, (d) motor speed and (e) electromagnetic torque.

With the motor reference speed equal to $100 \mathrm{rad} / \mathrm{sec}$, at $t=0.2 \mathrm{sec}$, a load torque step ranging from no-load to the rated load is introduced. At $t=0.4 \mathrm{sec}$, the load decreases from the rated value to a level of about $50 \%$ of the motor rated torque.

Also, with motor torque equal to $50 \%$ of the motor rated torque, two instantaneous speed changes are introduced. At $t=0.5 \mathrm{sec}$, a speed step from 100 $\mathrm{rad} / \mathrm{sec}$ to $145 \mathrm{rad} / \mathrm{sec}$ is introduced, and at $t=0.7$ $\mathrm{sec}$, the speed was decreased from $145 \mathrm{rad} / \mathrm{sec}$ to 100 $\mathrm{rad} / \mathrm{sec}$.

Nevertheless, even with these fast and strong transients in motor load and its speed, the diagnostic 
method behaves very well since the diagnostic variables are still far from the defined threshold of 0.06. Thus, it can be proved that this threshold value chosen empirically, can cope with very strong transients, preventing the method to emit false diagnostics.

\section{OTHER REMARKS}

\subsection{THRESHOLD VALUES SELECTION}

The correct algorithm diagnostic performance is critically dependent on the correct selection of the used threshold values. In a similar way to the majority of the existing open-circuit fault diagnostic techniques, the definition of the threshold values is accomplished by analyzing the diagnostic variables behavior for the healthy case and all faulty modes. Then, the values are set taking into account a tradeoff between a fast diagnosis and the robustness against the issue false alarms.

Hence, for the selection of $k_{f}$ value, the behavior of $E_{n}$ under normal operating conditions and for a single fault is considered. For these two cases, the average absolute values of these variables are between 0 and 0.2599 . This means that, theoretically, $k_{f}$ can have a value within this range, where a low value means fast detection speed but worse robustness against false diagnostics. On the contrary, a large value greatly increases the algorithm robustness but decreases its diagnostic speed. The recommended procedure that was followed in this paper consists in analyzing first the diagnostic variables behavior for the worst case scenario, presented in Fig. 7. It is known that the majority of the existing methods fail (by generating false alarms) for these extreme situations since there are very fast variations and the currents become very small, which lead to incorrect average values calculation.

All these problematic issues are presented for the transient shown in Fig. 7. From these results it can be verified that after the transient, the $E_{n}$ oscillations increase but their amplitude are always below 0.04 . This means that this value could be used for $k_{f}$, assuring a good diagnostic behavior for the other less extreme operating conditions. However, it is always better to consider a safety margin and therefore, the considered value of 0.06 can guarantee a much more robust diagnostic. On the other hand, the maximum value of $k_{f}$ should be lower than 0.2599 , since in practice the diagnostic variables may not reach this value. Considering all this and according to the obtained results, $k_{f}$ can be chosen within 0.04 and 0.24 .

The selection of $k_{s}$ is done by analyzing the behavior of the variables $S_{n}$ under normal operating conditions and for single faults. under normal operating conditions, the average values of $i_{n N}$ are equal 0 . For a single fault, the average values of $i_{n N}$ (corresponding to the faulty leg) will converge to 0.285 . Therefore, and taking also into account a safety margin, $k_{s}$ can be chosen to be higher than or equal 0.3 .

The threshold $k_{d}$ is the less important one since it is only used for same inverter leg double faults. Excluding these specific faults, it can be verified from the presented results that the values taken by $E_{n}$ are always greater than 0.5 . Hence, and assuring also a safety margin, $k_{d}$ can assume a value between 0.25 and 0.45 . It must be noticed that in order to maintain the diagnostic coherence, the condition $k_{f}<k_{d}$ must be verified.

As the diagnostic variables are normalized, these thresholds can be considered universal since they do not depend on the motor rated power, its operating load level and speed.

\subsection{ALGORITHM DETECTION SPEED}

The algorithm detection speed depends on the time instant of the fault occurrence. If a fault occurs during a positive current half-cycle and in the top IGBT of that phase, the effect can be clearly seen since the current tends immediately to zero. An equivalent result is also verified during a negative current half-cycle for a fault in the respective bottom transistor of that phase. For these cases, the detection and localization is, typically, relatively fast. However, if the fault occurs during a current halfcycle where the faulty IGBT does not immediately affect it, the fault effects will just be noticed at the next current half-cycle. Under these conditions, the fault can remain undetected for a period of time that can reach more than one-half of the motor phase currents fundamental period.

\section{CONCLUSION}

In this paper, a simple real-time fault diagnostic method for single and multiple opencircuit faults of a VSI-fed three-phase induction motor controlled by FOC has been presented.

The fault diagnostic algorithm can be easily integrated into the main control system without great effort. Just the motor phase current signals are used for diagnostic faults so, it does not require the use of extra voltage or any additional sensors, avoiding the subsequent increase of the drive system cost and complexity.

Also the diagnostic algorithm has other advantages such as the independence of the load and speed transients, simple tuning and a relatively fast diagnosis.

The presented simulation results allow successful verification of the proposed diagnostic method effectiveness. The work can be extended to other converter configurations or drives. 


\section{REFERENCES}

[1] B. M. Joshi, D. C. Patel, and M. C. Chandorkar," Machine interactions in field oriented controlled multi-machine three phase induction motor drives", IEEE International Electric Machines and Drives Conference, Miami, USA, pp. 342-347, May 2011.

[2] D. U. Campos-Delgado and D. R. Espinoza-Trejo, "An Observer-Based Diagnosis Scheme for Single and Simultaneous Open-Switch Faults in Induction Motor Drives", IEEE Transactions on Industrial Electronics, Vol. 58, No. 2, PP. 671-679, February 2011.

[3] R. L. Ribeiro et al., "Fault-tolerant voltage-fed PWM inverter ac motor drive systems", IEEE Transactions on Industrial Electronics, Vol. 51, No. 2, pp. 439-446, April 2004.

[4] B. Akin et al., "A simple real-time fault signature monitoring tool for motor-drive-embedded fault diagnosis systems", IEEE Transactions on Industrial Electronics, Vol. 58, No. 5, PP. 19902000, May 2011.

[5] G. Grandi, Y. Gritli, F. Filippetti, and C. Rossi, " Fault-tolerant operating analysis of a quad-inverter multiphase multilevel ac motor drive", IEEE International Symposium on Diagnostics for Electrical Machines, Power Electronics and Drives, Bologna, Italy, PP. 126-132, September 2011.

[6] H. B. A. Sethom and M. A. Ghedamsi, "Intermittent misfiring default detection and localisation on a PWM inverter using wavelet decomposition," Journal of Electrical Systems, Vol. 4, No. 2, pp. 222-234, 2008.

[7] S. Yang, A. Bryant, P. Mawby, X. Dawei, L. Ran, and P. Tavner, "An industry-based survey of reliability in power electronic converters," IEEE Transactions on Industry Applications, Vol. 47, No. 3, pp. 1441-1451, May/June 2011.

[8] S. Yang, D. Xiang, A. Bryant, P. Mawby, L. Ran, and P. Tavner, "Condition monitoring for device reliability in power electronic converters-A review," IEEE Transactions on Power Electronics, Vol. 25, No. 11, pp. 2734-2752, November 2010.

[9] N. M. A. Freire, J. O. Estima and A. J. Marques Cardoso, "Multiple open-circuit fault diagnosis in voltage-fed PWM motor drives using the current park's vector phase and the currents polarity", 8th IEEE International Symposium on Diagnostics for Electrical Machines, Power Electronics and Drives, Bologna, Italy, PP. 397-404, September 2011.

[10] W. Sleszynski et al., "Open-transistor fault diagnostics in voltage-source inverters by analyzing the load currents", IEEE Transactions on Industrial Electronics, vol. 56, no. 11, pp. 4681-4688, November 2009.

[11] A. M. S Mendes, A. J. M. Cardoso and E. S. Saraiva, "Voltage source inverter fault diagnosis in variable speed AC drives, by Park's vector approach," Seventh International Conference on Power Electronics and Variable Speed Drives,
London, UK, No. 456, PP. 538-543, September 1998.

[12] A. M. S. Mendes and A. J. M. Cardoso, "Voltage source inverter fault diagnosis in variable speed ac drives, by the average current Park's vector approach", IEEE International Electric Machines and Drives Conference, Seattle, WA, USA, No. 99, PP. 704-706, May 1999.

[13] J. A. A. Caseiro, A. M. S. Mendes and A. J. M. Cardoso, "Fault diagnosis on a PWM rectifier AC drive system with fault tolerance using the average current Park's vector approach", IEEE International Electric Machines and Drives Conference, Miami, USA, PP. 695-701, May 2009.

[14] D. Diallo, M. E. H. Benbouzid, D. Hamad, and X. Pierre, "Fault detection and diagnosis in an induction machine drive: a pattern recognition approach based on concordia stator mean current vector", IEEE Transactions on Energy Conversion, Vol. 20, No. 3, PP. 512-519, September 2005.

[15] F. Zidani, D. Diallo, M. E. H. Benbouzid, and R. Naït-Saïd, "A fuzzy-based approach for the diagnosis of fault modes in a voltage-fed PWM inverter induction motor drive", IEEE Transactions on Industrial Electronics, Vol. 55, No. 2, PP. 586-593, February 2008.

[16] K. Rothenhagen and F. W. Fuchs, "Performance of diagnosis methods for IGBT open circuit faults in three phase voltage source inverters for $\mathrm{AC}$ variable speed drives," Annual Power Electronics Specialists Conference, Dresden, Germany, PP. 110, 2005.

[17] W. Sleszynski, J. Nieznanski and A. Cichowski, "Open-transistor fault diagnostics in voltagesource inverters by analyzing the load currents", IEEE Transactions on Industrial Electronics, Vol. 56, PP. 4681-4688, November 2009.

[18] D. U. Campos-Delgado and D. R. Espinoza-Trejo, "An observer-based diagnosis scheme for single and simultaneous open-switch faults in induction motor drives," IEEE Transactions on Industrial Electronics, Vol. 58, No. 2, PP. 671-679, February 2011.

[19] M. A. Rodríguez-Blanco et al., "A failuredetection strategy for IGBT based on gate-voltage behavior applied to a motor drive system," IEEE Transactions on Industrial Electronics, Vol. 58, No. 5, PP. 1625-1633, May 2011.

[20] J. O. Estima and A. J. Marques Cardoso, "A new approach for real-time multiple open-circuit fault diagnosis in voltage source inverters", IEEE Transactions on Industry Applications, Vol. 47, No. 6, PP. 2487-2494, November/December 2011. 